\title{
Radiation-induced Oral Mucositis in Brazilian Patients: Prevalence and Associated Factors
}

\author{
IGOR FIGUEIREDO PEREIRA ${ }^{1}$, RAMON TARGINO FIRMINO ${ }^{2}$, HENRIQUE CORTES MEIRA ${ }^{3}$, \\ BELMIRO CAVALCANTI DO EGITO VASCONCELOS ${ }^{1}$, VLADIMIR REIMAR \\ AUGUSTO DE SOUZA NORONHA ${ }^{4}$ and VAGNER RODRIGUES SANTOS ${ }^{3}$ \\ ${ }^{1}$ Department of Prosthodontics and Bucco-Facial Surgery, School of Dentistry, \\ University of Pernambuco, Camaragibe, Brazil; \\ ${ }^{2}$ Department of Pediatric Dentistry and Orthodontics, School of Dentistry, \\ Federal University of Minas Gerais, Pampulha Belo Horizonte, Brazil; \\ ${ }^{3}$ Department of Clinical, Pathology and Surgery, School of Dentistry, \\ Federal University of Minas Gerais, Pampulha Belo Horizonte, Brazil; \\ ${ }^{4}$ Department of Surgery, University Center of Newton Paiva, Belo Horizonte, Brazil
}

\begin{abstract}
Aim: To determine the prevalence of radiationinduced oral mucositis (OM) and associated factors. Patients and Methods: A cross-sectional retrospective study was performed at a reference dental care center. The medical records of patients submitted to radiotherapy for the treatment of head and neck cancer were used to collect clinical and demographic variables. The data were submitted to descriptive analysis and multivariate Poisson regression with robust variance $[p<0.05 ; 95 \%$ confidence intervaI (CI)]. Results: Four hundred and thirteen patients were analyzed. The mean age was $55 \pm 14$ years. The prevalence of $\mathrm{OM}$ in the overall sample was $41.9 \%$ and was higher among males (78.2\%). The following variables were significantly associated with the outcome: radiation dose [prevalence ratio $(P R)=1.04 ; 95 \% \quad C I=1.02-1.06$ ]; concomitant chemotherapy $(P R=1.48,95 \% C I=1.05-2.08)$; oral candidiasis (PR=1.97, 95\% CI=1.44-2.68); and osteoradionecrosis $\quad(P R=1.51, \quad 95 \% \quad C I=1.10-2.06)$. Conclusion: Radiation-induced OM was associated with radiation dose, concomitant chemotherapy, oral candidiasis and osteoradionecrosis. The rate of OM underscores the
\end{abstract}

This article is freely accessible online.

Correspondence to: Igor Figueiredo Pereira, Department of Prosthodontics and Bucco Facial Surgery, University of Pernambuco, Av. Gal. Newton Cavalcanti, 1650, Tabatinga, Camaragibe, PE, 54756-220, Brazil. E-mail: figueiredo.ctbmf@gmail.com

Key Words: Radiotherapy, chemotherapy, epidemiology, head and neck cancer, oral mucositis. importance of adequate oral care prior to treatment for head and neck cancer.

Oral mucositis (OM) is one of the most significant and common complications of radio/chemotherapy for the treatment of head and neck cancer (1-3). The pathogenesis of OM is complex and related to xerostomia, which is a consequence of the impairment of the salivary glands caused by radiation. OM may occur during or after treatment, the debilitating adverse effects of which include severe pain as well as difficulties in eating and performing oral hygiene, thereby compromising quality of life and potentially leading to suspension of cancer treatment, which increases the risk of death $(4,5)$.

Data on the prevalence of radiation-induced OM in patients submitted to treatment for head and neck cancer are scarce in the literature and reveal considerable variation (6, 7). Recent studies have focused more on the different methods of cancer treatment rather than the causes of OM and associated factors $(8,9)$.

The oral regions most affected by OM are the floor of the mouth, lateral edge of the tongue, buccal mucosa and soft palate (10). Erythema is the initial manifestation, followed by the development of desquamative white plaques, which ulcerate, causing considerable pain. Poor oral hygiene and an absence of clinical follow-up before and during radiotherapy may aggravate the problem (8).

An in-depth investigation of OM would provide information for better clinical management of this complication, contributing to its prevention and improving the quality of life of patients $(9,10)$. Thus, the aim of the present study was to investigate the prevalence of radiationinduced OM and report its associated factors. 


\section{Patients and Methods}

The present study was reported according to the Strengthening the Reporting of Observational Studies in Epidemiology (STROBE) statement (11).

Study design and sample characteristics. A cross-sectional retrospective study was conducted involving data from patients who received dental care at the School of Dentistry of the Federal University of Minas Gerais (UFMG), Belo Horizonte, Brazil, which is a dental care reference center for patients with head and neck cancer. Data were collected from the medical records of all patients submitted to radiotherapy for the treatment of head and neck cancer between 2008 and 2017.

Data collection. The records were examined by a trained researcher who collected data on the following variables: Age, sex, type of malignancy, location of tumor, history of alcohol and tobacco use, radiation dose, occurrence of $\mathrm{OM}$ and tooth extractions before and after radiotherapy.

Statistical procedures. The data were analyzed using descriptive and inferential statistics with the aid of the Statistical Package for the Social Sciences (SPSS, version 23.0; IBM, Armonk, NY, USA). After the descriptive analysis, Poisson multiple regression analysis with robust variance was performed to determine associations between the dependent variable (OM) and the independent variables, considering a $5 \%$ level of significance $(p<0.05)$. Variables with a $p$-value of less than 0.20 in the bivariate analysis were incorporated into the multiple analysis and those with a p-value of less than 0.05 remained in the final model. Prevalence ratios (PR) and respective $95 \%$ confidence intervals (CI) were calculated.

Ethical aspects. This study was performed in compliance with the ethical precepts stipulated in Resolution 466/12 of the Brazilian National Health Council and Declaration of Helsinki. The investigation only included information from medical records that were correctly filled out and had the patient's authorization in the form of a signed statement of informed consent. This study received approval from the Human Research Ethics Committee of the Federal University of Minas Gerais (certificate number: 47197715.0.0000.5149)

\section{Results}

A total of 413 medical records of patients submitted to radiotherapy for the treatment of head and neck cancer between January 2008 and December 2017 were evaluated. Table I displays the clinical characteristics of the patients, malignant lesions and main complications of treatment. The prevalence of OM in the overall sample was $41.9 \%(n=173)$ and was higher among males $(78.2 \%)$. The mean age was $55 \pm 14$ years. Squamous cell carcinoma was the most frequent type of tumor $(76.3 \% ; \mathrm{n}=315)$ and the oral cavity was the most frequent location $(42.2 \% ; n=174)$. The frequencies of osteoradionecrosis and oral candidiasis were $9.7 \%$ and $17.9 \%$, respectively. The mean number of teeth extracted was 10 .
Table I. Clinical characteristics of patients and the main complications of the treatment of head and neck cancer from the School of Dentistry of the Federal University of Minas Gerais ( $n=413)$.

\begin{tabular}{|c|c|}
\hline Variable & Value \\
\hline \multicolumn{2}{|l|}{ Gender, n (\%) } \\
\hline Female & $90(21.8)$ \\
\hline Male & $323(78.2)$ \\
\hline \multicolumn{2}{|l|}{ Age, n $(\%)$} \\
\hline$\leq 55$ Years & $207(50.1)$ \\
\hline$>55$ Years & $206(49.9)$ \\
\hline \multicolumn{2}{|l|}{ Oral mucositis, n (\%) } \\
\hline Present & $173(41.9)$ \\
\hline Absent & $240(58.1)$ \\
\hline \multicolumn{2}{|l|}{ Osteoradionecrosis, n (\%) } \\
\hline Present & $40(9.7)$ \\
\hline Absent & $373(78.2)$ \\
\hline \multicolumn{2}{|l|}{ Type of cancer, n (\%) } \\
\hline Other & $98(23.7)$ \\
\hline SCC & $315(76.3)$ \\
\hline \multicolumn{2}{|l|}{ Site of tumor, n (\%) } \\
\hline Other & $238(57.8)$ \\
\hline Oral cavity & $174(42.2)$ \\
\hline History of alcohol use, $\mathrm{n}(\%)$ & No \\
\hline \multicolumn{2}{|l|}{$64(15.5)$} \\
\hline Yes & $349(84.5)$ \\
\hline \multicolumn{2}{|l|}{ Smoking, n (\%) } \\
\hline No & $44(10.7)$ \\
\hline Yes & $158(38.3)$ \\
\hline Stopped & $211(51.1)$ \\
\hline \multicolumn{2}{|l|}{ Chemotherapy, n (\%) } \\
\hline No & $200(48.4)$ \\
\hline Yes & $213(51.6)$ \\
\hline \multicolumn{2}{|l|}{ Oral candidiasis, $\mathrm{n}(\%)$} \\
\hline No & $339(82.1)$ \\
\hline Yes & 74 (17.9) \\
\hline \multicolumn{2}{|c|}{ Visited the dentist before radiation, $\mathrm{n}(\%)$} \\
\hline No & $220(53.3)$ \\
\hline Yes & $193(46.7)$ \\
\hline \multicolumn{2}{|c|}{ Removed teeth before radiation, $\mathrm{n}(\%)$} \\
\hline No & $2(1.1)$ \\
\hline Yes & $186(98.9)$ \\
\hline \multicolumn{2}{|l|}{ Radiation dose, Gy } \\
\hline Mean \pm SD & $60.43 \pm 8.23$ \\
\hline \multicolumn{2}{|l|}{ Number of sessions } \\
\hline Mean \pm SD & $30.53 \pm 5.36$ \\
\hline \multicolumn{2}{|l|}{ Number of teeth removed } \\
\hline Mean \pm SD & $9.97 \pm 6.55$ \\
\hline
\end{tabular}

SCC: Squamous cell carcinoma.

The following risk factors were significantly associated with OM: osteoradionecrosis $(\mathrm{PR}=1.51,95 \% \mathrm{CI}=1.10$ 2.06), chemotherapy ( $\mathrm{PR}=1.48,95 \% \mathrm{CI}=1.05$ to 2.08$)$, oral candidiasis $(\mathrm{PR}=1.97,95 \% \mathrm{CI}=1.44-2.68)$, and radiation dose $(\mathrm{PR}=1.04 ; 95 \% \mathrm{CI}=1.02$ to 1.06$)$. The extraction of compromised teeth prior to radiotherapy was a factor protective against $\mathrm{OM}(\mathrm{PR}=0.36 ; 95 \% \quad \mathrm{CI}=0.24-0.54)$ (Table II). 
Table II. Bivariate and multivariate Poisson regression analysis regarding the association of oral mucositis and independent variables among patients undergoing radiotherapy from the School of Dentistry of the Federal University of Minas Gerais ( $n=413)$.

\begin{tabular}{|c|c|c|c|c|c|c|}
\hline \multirow[b]{2}{*}{ Independent variable } & \multicolumn{2}{|c|}{ Oral mucositis } & \multicolumn{2}{|c|}{ Unadjusted* } & \multicolumn{2}{|c|}{ Adjusted** } \\
\hline & Yes $(n=173)$ & No $(n=240)$ & PR $(95 \% \mathrm{CI})$ & $p$-Value & PR $(95 \% \mathrm{CI})$ & $p$-Value \\
\hline \multicolumn{7}{|l|}{ Gender, n (\%) } \\
\hline Female & $38(42.2)$ & $52(57.8)$ & 1.00 & & & \\
\hline Male & $135(41.8)$ & $188(58.2)$ & $1.226(0.723-2.080)$ & 0.449 & & \\
\hline \multicolumn{7}{|l|}{ Age, n (\%) } \\
\hline$\leq 55$ Years & $89(43.0)$ & $118(57.0)$ & $1.252(0.872-1.797)$ & 0.224 & & \\
\hline$>55$ Years & $84(40.8)$ & $122(59.6)$ & 1.00 & & & \\
\hline \multicolumn{7}{|l|}{ Type of cancer, n (\%) } \\
\hline Other & $37(37.8)$ & $61(62.2)$ & 1.00 & & & \\
\hline $\mathrm{SCC}$ & $136(43.2)$ & $179(56.8)$ & $1.119(0.693-1.808)$ & 0.644 & & \\
\hline \multicolumn{7}{|l|}{ Site of tumor, n (\%) } \\
\hline Other & $94(39.5)$ & $144(60.5)$ & 1.00 & & & \\
\hline Oral cavity & $78(44.8)$ & $96(55.2)$ & $1.052(0.747-1.482)$ & 0.771 & & \\
\hline \multicolumn{7}{|c|}{ History of alcohol use, n (\%) } \\
\hline No & $22(33.4)$ & $42(65.6)$ & 1.00 & & & \\
\hline Yes & $151(43.3)$ & $198(56.7)$ & $1.456(0.766-2.767)$ & 0.252 & & \\
\hline \multicolumn{7}{|l|}{ Smoking, n (\%) } \\
\hline No & $13(29.5)$ & $31(70.5)$ & 1.00 & & & \\
\hline Yes & $64(40.5)$ & $94(59.5)$ & $1.562(0.628-3.889)$ & 0.337 & & \\
\hline Stopped & $96(45.5)$ & $115(54.5)$ & $2.125(0.881-5.123)$ & 0.093 & & \\
\hline \multicolumn{7}{|c|}{ Osteoradionecrosis, n (\%) } \\
\hline No & $143(38.3)$ & $230(61.7)$ & 1.00 & & 1.00 & \\
\hline Yes & $30(75.0)$ & $10(25.0)$ & $1.946(1.422-2.665)$ & $<0.001$ & $1.388(1.025-1.881)$ & 0.034 \\
\hline \multicolumn{7}{|l|}{ Chemotherapy, n (\%) } \\
\hline No & $68(34.0)$ & $132(66.0)$ & 1.00 & & 1.00 & \\
\hline Yes & $105(49.3)$ & $108(50.7)$ & $1.611(1.106-2.346)$ & 0.013 & $1.459(1.024-2.079)$ & 0.037 \\
\hline \multicolumn{7}{|l|}{ Oral candidiasis, $\mathrm{n}(\%)$} \\
\hline No & $120(35.4)$ & $219(64.6)$ & 1.00 & & 1.00 & \\
\hline Yes & $53(71.6)$ & $21(28.4)$ & $2.281(1.728-3.012)$ & $<0.001$ & $1.886(1.411-2.522)$ & $<0.001$ \\
\hline \multicolumn{7}{|c|}{ Teeth removed before radiation, $\mathrm{n}(\%)$} \\
\hline No & $2(100.0)$ & $0(0)$ & 1.00 & & 1.00 & \\
\hline Yes & $76(40.9)$ & $110(59.1)$ & $0.418(0.352-0.496)$ & $<0.001$ & $0.376(0.293-0.483)$ & $<0.001$ \\
\hline \multicolumn{7}{|c|}{ Visited the dentist before radiation, $\mathrm{n}(\%)$} \\
\hline No & $94(42.7)$ & $126(57.3)$ & 1.00 & & & \\
\hline Yes & $79(40.9)$ & $114(59.1)$ & $0.849(0.210-3.431)$ & 0.818 & & \\
\hline \multicolumn{7}{|l|}{ Radiation dose } \\
\hline Mean \pm SD & $64.99 \pm 6.47$ & $56.96 \pm 7.73$ & $1.061(1.037-1.085)$ & $<0.001$ & $1.039(1.021-1.058)$ & $<0.001$ \\
\hline \multicolumn{7}{|l|}{ Number of sessions } \\
\hline Mean \pm SD & $32.72 \pm 4.93$ & $28.86 \pm 5.075$ & $1.034(1.012-1.055)$ & 0.002 & $1.028(1.009-1.047)$ & 0.004 \\
\hline
\end{tabular}

PR: Prevalence ratio; CI: confidence interval. *Unadjusted Poisson regression analysis. **Variables incorporated in multivariate model $(p<0.20)$ : osteoradionecrosis, radiation dose, teeth removed before radiation, candidiasis, number of sessions, chemotherapy, smoking, history of alcohol use.

\section{Discussion}

The main objective of the most recent studies in the field of head and neck cancer has been the search for new treatment modalities and the investigation of complications (12-14). Epidemiological studies on the prevalence of complications are less common (15).

The prevalence of radiation-induced $\mathrm{OM}$ in the present study was $41.9 \%$. This finding differs from rates reported in the literature, in which a frequency of nearly $100 \%$ is often reported $(16,17)$. While the treatment of OM is not well established (9), individualized follow-up of patients before, during and after radiotherapy may contribute to greater control of complications stemming from treatment (18). The lower frequency of radiation-induced $\mathrm{OM}$ in the present study reflects the importance of adequate dental care before, during and after radiotherapy.

OM was more frequent among males. Previous studies also found a higher occurrence of $\mathrm{OM}$ in males, with reports of approximately 60\% (17) and 89\% (18). The higher prevalence in men can be explained by the greater occurrence of harmful habits attributed to this sex, such as 
poor hygiene, smoking and alcohol abuse, as well as a less frequent use of dental services (19).

A further aim of the present study was to report factors associated with radiation-induced OM. The oral cavity was the site most affected by malignant tumors. Mercadante et al. (7) report that head and neck tumors are often related to $\mathrm{OM}$ due to the proximity of the oral cavity to the radiation field (20). Moreover, an association was found between the prevalence of OM and higher doses of radiation, which is similar to data reported in previous studies $(9,15,21)$. This can be explained by the fact that radiation destroys epithelial cells, causing desquamation and ulceration. High doses of radiation also cause greater changes in the salivary glands, leading to hyposalivation and, consequently, OM (22).

The prevalence of $\mathrm{OM}$ among patients having undergone chemotherapy as adjuvant treatment was approximately $50 \%$ higher compared to those who did not undergo chemotherapy. Studies report that chemotherapy combined with radiotherapy produces better results in the treatment of head and neck cancer. However, the occurrence of side-effects is greater when the two therapies are combined. In addition to the direct aggression caused by radiotherapy, chemotherapy systematically compromises the body, leaving the patient more prone to complications $(7,15)$.

Good oral health status is very important prior to radiotherapy in the head and neck region $(23,24)$. For such, it is necessary to remove any teeth that should not remain in the oral cavity (25). A previous study reported an average of eight teeth removed per patient prior to radiotherapy (26). In the present study, a similar result was observed, with an average of 10 teeth removed. The extraction of teeth prior to the initiation of radiotherapy was a protective factor in the present study, as the prevalence of OM was lower in such cases. However, it is important to remember that individuals undergoing dental care before head and neck radiation need to have a close follow-up to avoid possible complications (10).

The prevalence of osteoradionecrosis was low (9.7\%), which is similar to the rate reported in a German study (12\%) (26), but much higher than that reported in a study conducted in the United States (1.2\%) (27). This divergence may be explained by the different modalities of radiotherapy treatment, the presence/absence of previous oral care, the study design, sample characteristics and methods employed for diagnosing OM. In the present investigation, the prevalence of OM was 1.5-fold higher among patients with osteoradionecrosis than those without this condition. Previous studies involving patients with osteoradionecrosis have also reported a high prevalence rate of OM $(25,26)$. A possible explanation for this is the high doses of radiation that patients received, leading to the concomitant development of the two complications of treatment. Moreover, an association has been reported between OM and local or systemic infection (28), which also predisposes patients to osteoradionecrosis (10).

The prevalence of oral candidiasis associated with $\mathrm{OM}$ ranges from $27-50 \%$ (29-31), which is higher than the rate found in the present study. Nonetheless, patients with oral candidiasis were nearly twice as likely to have OM compared to those without this condition. Oral candidiasis lesions often overlap with those of radiation-induced OM and the differentiaI diagnosis between the two is quite difficult. Therefore, it is very common to associate these complications (31).

$\mathrm{OM}$ is the most common complication and one of the most debilitating side-effects of head and neck cancer treatment (3). Therefore, the investigation of predisposing factors, as well as adequate dental care before and during radiotherapy, can contribute to a reduction in the occurrence of this complication and an improvement in the quality of life of patients.

In conclusion, radiation-induced OM was associated with the radiation dose, concomitant chemotherapy, oral candidiasis and osteoradionecrosis. The extraction of compromised teeth prior to treatment was a protective factor against this complication. The lower rate of $\mathrm{OM}$ in the present investigation when compared to that reported in previous studies underscores the importance of adequate oral care prior to treatment for head and neck cancer.

\section{Conflicts of Interests}

IFP confirms on behalf of all the Authors that there are no conflicts of interest in regard to this work.

\section{Acknowledgements}

The helpful comments on an earlier version of this article from anonymous reviewers are gratefully acknowledged. This study was supported by the University of Minas Gerais and University of Pernambuco, Brazil.

\section{References}

1 Carneiro-Neto JN, de-Menezes JD, Moura LB, Massucato EM and de-Andrade CR: Protocols for management of oral complications of chemotherapy and/or radiotherapy for oral cancer: Systematic review and meta-analysis current. Med Oral Patol Oral Cir Bucal 22: 15-23, 2017.

2 Donetti E, Bedoni M, Capone P, Gualerzi A, Tartaglia G and Sforza C: An in vitro model of human oral explants to study early effects of radiation mucositis. Eur J Oral Sci 117: 169-174, 2009.

3 Handschel J, Sunderkötter C, Kruse-Lösler B, Prott FJ, Meyer $\mathrm{U}$, Piffko $\mathrm{J}$ and Joos U: Late effects of radiotherapy on oral mucosa in humans. Eur J Oral Sci 109: 95-102, 2001.

4 Mosel DD, Bauer RL, Lynch DP and Hwang ST: Oral complications in the treatment of cancer patients. Oral Dis 17: 550-559, 2011.

5 Hanchanale S, Adkinson L, Daniel S, Fleming M and Oxberry SG: Systematic literature review: Xerostomia in advanced cancer patients. Support Care Cancer 23: 881-888, 2015. 
6 Nicolatou-Galitis O, Velegraki A, Sotiropoulou-Lontou A, Dardoufas K, Kouloulias V, Kyprianou K, Kolitsi G, Skarleas C, Pissakas G, Papanicolaou VS and Kouvaris J: Effect of fluconazole antifungal prophylaxis on oral mucositis in head and neck cancer patients receiving radiotherapy. Support Care Cancer 14: 44-51, 2006.

7 Mercadante S, Aielli F, Adile C, Ferrera P, Valle A, Fusco F, Caruselli A8, Cartoni C, Massimo P, Masedu F, Valenti M and Porzio G: Prevalence of oral mucositis, dry mouth, and dysphagia in advanced cancer patients. Support Care Cancer 23: 3249-3255, 2015.

8 Keefe DM, Schubert MM, Elting LS, Sonis ST, Epstein JB, RaberDurlacher JE, Migliorati CA, McGuire DB, Hutchins RD and Peterson DE: Updated clinical practice guidelines for the prevention and treatment of mucositis. Cancer 109: 820-831, 2007.

9 Jensen SB and Peterson DE: Oral mucosal injury caused by cancer therapies: Current management and new frontiers in research. J Oral Pathol Med 43: 81-90, 2014.

10 Moslemi D, Nokhandani AM, Otaghsaraei MT, Moghadamnia Y, Kazemi S and Moghadamnia AA: Management of chemo/radiationinduced oral mucositis in patients with head and neck cancer: A review of the current literature. Radiother Oncol 120: 13-20, 2016

11 Vandenbroucke JP1, von Elm E, Altman DG, Gøtzsche PC, Mulrow CD, Pocock SJ, Poole C, Schlesselman JJ, Egger M; STROBE Initiative. Strengthening the Reporting of Observational Studies in Epidemiology (STROBE): Explanation and elaboration. Epidemiology 18: 805-835, 2007.

12 Svanberg A, Öhrn K and Birgegård G: Caphosol (®) mouthwash gives no additional protection against oral mucositis compared to cryotherapy alone in stem cell transplantation. A pilot study. Eur J Oncol Nurs 19: 50-53, 2015.

13 Henke M, Alfonsi M, Foa P, Giralt J, Bardet E, Cerezo L, Salzwimmer M, Lizambri R, Emmerson L, Chen MG and Berger D: Palifermin decreases severe oral mucositis of patients undergoing postoperative radiochemotherapy for head and neck cancer: A randomized, placebocontrolled trial. J Clin Oncol 29: 2815-2820, 2011.

14 Epstein JB, Thariat J, Bensadoun RJ, Barasch A, Murphy BA and Kolnick L: Oral complications of cancer and cancer therapy: From cancer treatment to survivorship. CA Cancer J Clin 62 : 400-422, 2012.

15 Al-Ansari S, Zecha JA, Barasch A, de Lange J, Rozema FR and Raber-Durlacher JE: Oral mucositis induced by anticancer therapies. Curr Oral Health Rep 2: 202-211, 2015.

16 Feller L, Essop R, Wood NH, Khammissa RA, Chikte UM, Meyerov R and Lemmer J: Chemotherapy-and radiotherapyinduced oral mucositis: pathobiology, epidemiology and management. SADJ 65: 372-374, 2010.

17 Nicolatou-Galitis O, Kouloulias V, Sotiropoulou-Lountou A, Dardoufas K, Polychronopoulou A, Athanassiadou P, Kolitsi G and Kouvaris J: Oral mucositis, pain and xerostomia in 135 head and neck cancer patients receiving radiotherapy with or without chemotherapy. Open Cancer J 4: 7-17, 2011.

18 De Sanctis V, Bossi P, Sanguineti G, Trippa F, Ferrari D, Bacigalupo A, Ripamonti CI, Buglione M, Pergolizzi S, Langendjik JA, Murphy B, Raber-Durlacher J, Russi EG and Lalla RV: Mucositis in head and neck cancer patients treated with radiotherapy and systemic therapies: Literature review and consensus statements. Crit Rev Oncol Hematol 100: 147-166, 2016.

19 Wuketich S, Hienz SA and Marosi C: Prevalence of clinically relevant oral mucositis in outpatients receiving myelosuppressive chemotherapy for solid tumors. Support Care Cancer 20: 175183,2012
20 Rosenthal DI: Consequences of mucositis-induced treatment breaks and dose reductions on head and neck cancer treatment outcomes. J Support Oncol 9: 23-31, 2007.

21 Harada K, Ferdous T, Horinaga D, Uchida K, Mano T, Mishima K, Park S, Hanazawa H, Takahashi S, Okita A, Fukunaga M, Maruta J, Kami N, Shibuya K and Ueyama Y: Efficacy of elemental diet on prevention for chemoradiotherapy-induced oral mucositis in patients with oral squamous cell carcinoma. Support Care Cancer 24: 953-959, 2016.

22 Kataoka T, Kiyota N, Shimada T, Funakoshi Y, Chayahara N, Toyoda M, Fujiwara Y, Nibu K, Komori T, Sasaki R, Mukohara T and Minami H: Randomized trial of standard pain control with or without gabapentin for pain related to radiation-induced mucositis in head and neck cancer. Auris Nasus Larynx 43: 677-684, 2016.

23 Jham BC, Reis PM, Miranda EL, Lopes RC, Carvalho AL, Scheper MA and Freire AR: Oral health status of 207 head and neck cancer patients before, during and after radiotherapy. Clin Oral Investig 12: 19-24, 2008.

24 Noronha VR, Araujo GS, Gomes RT, Iwanaga SH, Barbosa MC, Abdo EN, Ferreira e Ferreira E, Viana Campos AC, Souza AA, Abreu SR and Santos VR: Mucoadhesive propolis gel for prevention of radiation-induced oral mucositis. Cur Clin Pharmacol 9: 359-364, 2014.

25 Nabil S and Samman N: Risk factors for osteoradionecrosis after head and neck radiation: A systematic review. Oral Surg Oral Med Oral Pathol Oral Radiol 113: 54-69, 2012.

26 Niewald M, Fleckenstein J, Mang K, Holtmann H, Spitzer WJ and Rübe C: Dental status, dental rehabilitation procedures, demographic and oncological data as potential risk factors for infected osteoradionecrosis of the lower jaw after radiotherapy for oral neoplasms: a retrospective evaluation. Radiat Oncol 2: 227, 2013.

27 Gomez DR, Estilo CL, Wolden SL, Zelefsky MJ, Kraus DH, Wong RJ, Shaha AR, Shah JP, Mechalakos JG and Lee NY: Correlation of osteoradionecrosis and dental events with dosimetric parameters in intensity-modulated radiation therapy for head-and-neck cancer. Int J Radiat Oncol Biol Phys 81: 207-213, 2011.

28 Vanhoecke B, De Ryck T, Stringer A, Van de Wiele T and Keefe D: Microbiota and their role in the pathogenesis of oral mucositis. Oral Dis 21: 17-30, 2015.

29 Dahiya MC, Redding SW, Dahiya RS, Eng TY, Kirkpatrick WR, Coco BJ, Sadkowski LC, Fothergill AW, Waite A, Rinaldi MG, Patterson TF and Thomas CR: Oropharyngeal candidiasis caused by non-albicans yeast in patients receiving external beam radiotherapy for head-and-neck cancer. Int J Radiat Oncol Biol Phys 57: 79-83, 2003.

30 Nicolatou-Galitis O, Sotiropoulou-Lontou A, Velegraki A, Pissakas G, Kolitsi G, Kyprianou K, Kouloulias V, Papanikolaou I, Yiotakis I and Dardoufas K: Oral candidiasis in head and neck cancer patients receiving radiotherapy, with amifostine cytoprotection. Oral Oncol 39: 397-401, 2003.

31 Jham BC, França EC, Oliveira RR, Santos VR, Kowalski LP and da Silva Freire AR: Candida oral colonization and infection in Brazilian patients undergoing head and neck radiotherapy: a pilot study. Oral Surg Oral Med Oral Pathol Oral Radiol Endod 103: 355-358, 2007.

Received December 13, 2018

Revised December 27, 2018

Accepted January 7, 2019 